\title{
Research of the Transient Temperature Field and Friction Properties on Disc Brakes
}

\author{
Zhang Jian \\ School of Automobile and Traffic Engineering \\ Jiangsu University \\ Zhenjiang, Jiangsu, China \\ jzhangyangtze@126.com
}

\author{
Xia Changgao \\ School of Automobile and Traffic Engineering \\ Jiangsu University \\ Zhenjiang, Jiangsu, China \\ xiacg@ujs.edu.cn
}

\begin{abstract}
According to the real dimension of the braking disc, the finite element modeling for three-dimensional transient cyclic symmetry during the long downhill braking is established. The distribution of the transient temperature field of the brake disc during the braking are analyzed. The variation of the friction factor combined with the temperature characteristics of the friction factor during the braking are analyzed. The analysis result show: During the braking, the temperature of the brake rises increasingly and reaches the top temperature of $316.04^{\circ} \mathrm{C}$ at the end of braking process, the high temperature section concentrates in the far area of the friction surface; The changes of the friction factor is relatively stable during the long downhill braking. There is no obvious thermal recession. (Abstract)
\end{abstract}

Keywords- Disc brake; Transient temperature field; Friction properties (key words)

\section{INTRODUCTION}

The braking performance of the automotive is one of the most important factors that affected the traffic safety and the brake is the key components related to the running safety of the automotive. It was found that the $50 \%$ is caused by braking according to the analysis of the deviation and sideslip accident analysis. It is mostly due to the thermal fatigue failure cause brake failure caused by traffic accident. The numerical simulation of the temperature field is the main method of solving the brake thermal recession and thermal fatigue. The biggest difficulty is the analysis of the transient and alternating temperature field during the braking process and the establishment of a simplified model of the thermal structural coupling.

The research of the thermal-structural coupled field in foreign focused on the thermal elastic instability and the analysis of "hot spots" of the brake disc production principle and the critical conditions. Domestic researches mainly focus on the analysis of the temperature field and stress field. The 3D transient temperature and stress field finite element model was established by the numerical simulation. The coupled characteristics of the friction heat flow between the disk and pad as well as the effects of the brake disc thermal stress because of the variable moving speed was considered. The change varies with temperature of material parameters and the friction coefficient was considered. At the same time, the model was optimized by the experiment. Because of the temperature field of brake is a complex friction heat and related to the highly nonlinear. In order to calculate the convergence results, the inputting of friction heat was defined in the form of function in the finite element software. In order to simulate the change of the temperature field of the because of the disc brake inputting of the transient heat flux and the alternating change of convection heat. APDL program was used to achieve the circumferential uniform deceleration and circular movement of the heat flux load.

The 3D transient and cyclic symmetry finite element model of the temperature field of the ventilation caliper disc brake in a long downhill braking condition was established in this paper. The distribution of the transient temperature field of the brake disc during the braking are analyzed. The variation of the friction factor combined with the temperature characteristics of the friction factor during the braking are analyzed.

\section{THE ESTABLISHMENT OF FINITE ELEMENT MODEL}

\section{A. Meshing}

A simplified three-dimensional finite element model of brake disc was established. the thermal element solid70 are used to mesh the disc structure, the surface effect element surface152 are established on the contact interface, the density of heat flux is loaded on the surface of solid element, heat transfer coefficient is loaded on the surface of surface effect element. The braking force between disc and pad is considered by equivalent density of heat flux, so the meshing does not include in pad.

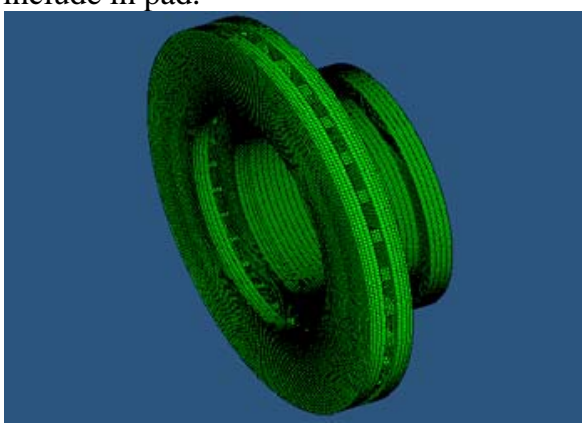

Figure 1. The finite element model of disk brake

\section{B. Heat flux density}

The density of heat flux is calculated by using the energy conversion method, heat flux is the $2 \mathrm{D}$ function changed 
with time and friction distance in the radial direction, the speed of vehicle is constant under long downhill braking process, heat flux just changes with friction radius, as in

$$
q(t)=\eta \frac{\beta}{4 A} M g(i-f) \mathrm{r} \omega
$$

Where, $\eta$ is coefficient of the thermal conductivity of the contact interface; $\beta$ is the distribution coefficient of braking force; $A$ is contact area; $M$ is axle weight; $I$ is slope; $f$ is the coefficient of rolling resistance; $r$ is rolling radius; $\omega$ is angular velocity.

The coefficient of the thermal conductivity of the contact interface is set to be correlated with the contact pressure. In the braking process, the total heat generated by braking is distributed to each part of the contact pairs, the distribution coefficient $\eta$ is, as in

$$
\eta=\frac{q_{d}}{q_{p}}=\sqrt{\frac{k_{d}{ }^{{ }_{d}} \rho_{d}}{k_{p}{ }^{c}{ }_{p} \rho_{p}}}
$$

In the above equation, $\rho$ is density, $c$ is specific heat, $k$ is thermal conductivity, and subscripts $d$ and $p$ identify the disc and pad, respectively.

\section{Heat transfer coefficient}

The heat transfer coefficient is a parameter relates with the velocity of air and the shape of brake disc. In different velocity of air, the heat transfer coefficient in different parts of brake disc changes with time, heat transfer coefficient relates with angular velocity is calculated as in

$$
h_{c}=\left\{\begin{array}{l}
6.725 \omega^{0.55}, 0 \leq \omega \leq 46.36 \mathrm{rad} / \mathrm{s} \\
3.289 \omega^{0.90}, \omega>46.36 \mathrm{rad} / \mathrm{s}
\end{array}\right.
$$

Where, $\omega$ is angular velocity of the disc. The speed of vehicle is constant under long downhill braking process, coefficient of heat transfer is constant and unrelated to time. The coefficient of heat transfer $h_{c}=108.04 \mathrm{w} / \mathrm{m}^{2}{ }^{\circ} \mathrm{C}$.

III. ANALYSIS OF TRANSIENT TEMPERATURE FIELD OF BRAKE DISC

\section{A. The temperature distribution of brake disc}

Braking generates a amount of friction heat makes the brake temperature rise sharply, and results in high local temperature, thermal degradation and thermal injury, and even damage. It assumes that the speed of vehicle $v_{0}$ is $30 \mathrm{~km} / \mathrm{h}$, coefficient of road slope is $6 \%$, continuous running distance is $6 \mathrm{~km}$ in this paper. The temperature distribution of brake disc in a long downhill braking condition at 720s is as shown in fig2. The high temperature mainly concentrate in the surface edge of brake disc. The temperature of brake disc on surface increases with the increasing of radial size. the highest temperature reaches to $316.04^{\circ} \mathrm{C}$, the temperature of inner edge reaches $250.07{ }^{\circ} \mathrm{C}$. The highest temperature of radiating rib in brake disc reaches to $291.31^{\circ} \mathrm{C}$.

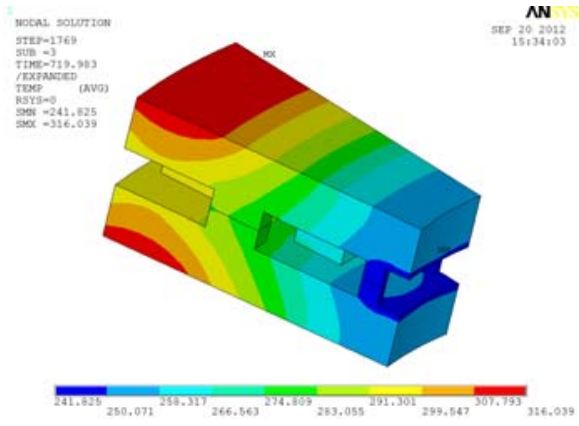

Figure 2. The temperature contours at 720 s

\section{B. The distribution state of temperature in the radial direction}

The temperature-time curve of the nodes in the radial direction is as shown in fig3,resulting from the combined influence of the heat input into the rotor's surface and the heat convection, the overall trend shows ascendant state. The friction heat on surface increases with the increasing of tangential velocity, the tangential velocity near the inner diameter is small, so the temperature near the inner diameter is low and the temperature near the outside diameter is high. The temperature of nodes in the edge is slightly less than the maximum temperature because of convection between the edge and air.

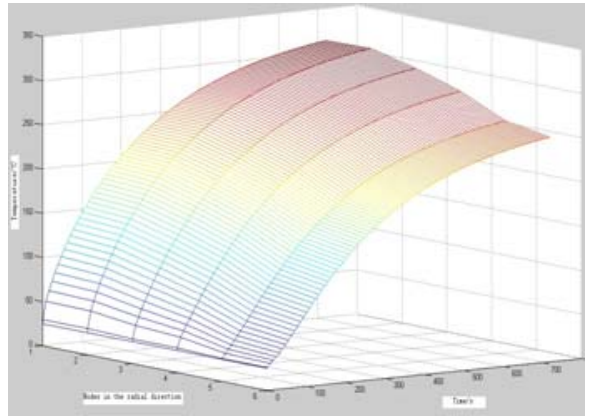

Figure 3. Time-Temperature curve of nodes in the radial direction

\section{The distribution state of temperature in the axial direction}

The temperature-time curve of the nodes in the axial direction is as shown in fig4. The speed of friction generates heat is faster than the speed of heat conduction, so the temperature outside is higher than the temperature inside. The temperature outside decreases quickly because of the braking time is very long, the cooling condition in surface is good during the braking period. The distribution state of temperature in the axial direction is nearly uniform. 


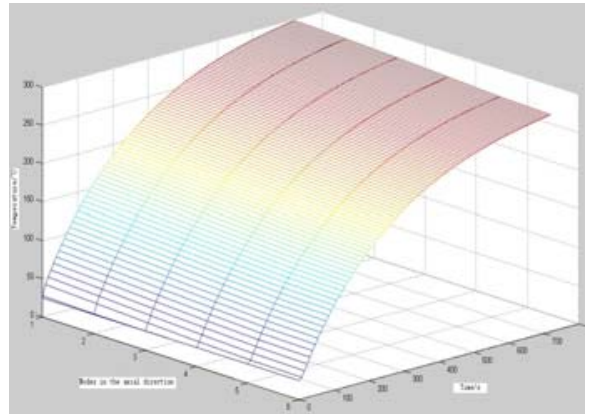

Figure 4. Time-Temperature curve of nodes in the axial direction

\section{FRICTION PERFORMANCE ANALYSIS UNDER DIFFERENT SLOPE}

\section{A. The relationship between friction factor and temperature}

Many factors affect the friction factor, the temperature of friction surface is the most significant. The normal pressure and relative sliding velocity between disc and pad affect the friction factor by affecting the temperature. The temperaturefriction factor curve is as in

$$
\mu=A_{4} T^{4}+A_{3} T^{3}+A_{2} T^{2}+A_{1} T+A_{0}
$$

In the above equation, $A_{0} 、 A_{1} 、 A_{2} 、 A_{3} 、 A_{4}$ are undetermined coefficient, they were determined by bench test; $\mathrm{T}$ is the temperature of friction surface. The timefriction factor curve of material HT250 of brake disc is as shown in fig5. The figure shows, the recession of friction factor is nonlinear variation.

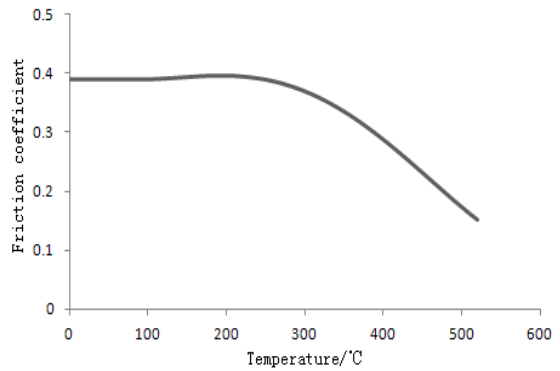

Figure 5. Temperature characteristic curve of the friction factor

\section{B. The average maximum temperature of friction surface}

The distribution state of temperature in the contact interface is not uniform because of the combined influence of the heat input into the rotor's surface and the heat convection. In order to achieve the uniform distribution of temperature, it is simplified that heat input and heat convection happen in contact interface at the same time. Under different slope, the curve of average maximum temperature of contact interface and time is as shown in fig6. The temperature in the contact interface increases nonlinearly with the braking time increases. The slope is $5 \%$, the maximum value is $246.74{ }^{\circ} \mathrm{C}$; the slope is $6 \%$, the maximum value is $316.04^{\circ} \mathrm{C}$; the slope is $7 \%$, the maximum value is $385.33^{\circ} \mathrm{C}$.

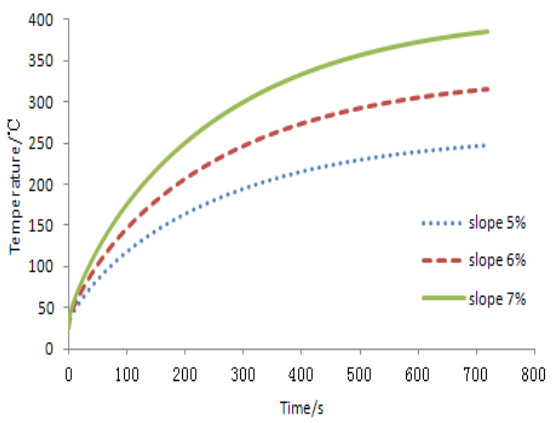

Figure 6. The curve of average maximum temperature of friction surface and time

\section{The analysis of friction factor during braking process}

According to the curve of average maximum temperature of contact interface and time, combined with the temperature characteristic curve of the friction coefficient, the friction coefficient varied with time is calculated during braking process under different slope. As shown in fig7, at the beginning of braking, friction coefficient increases slowly and decrease with the increasing of braking time. The disc brake has a good performance of convection heat transfer, the change of temperature is not very large during a long downhill braking process, friction coefficient is always stable within a reasonable range, the obvious thermal recession is not happened.

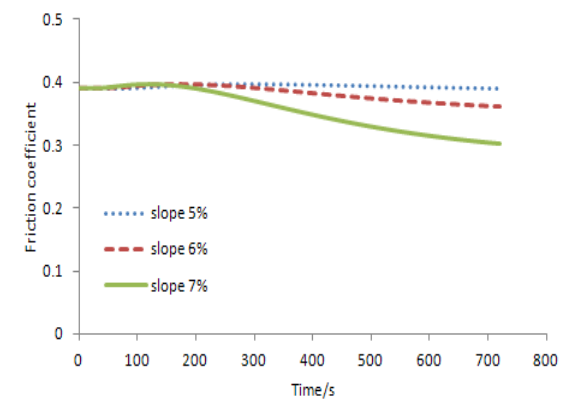

Figure 7. The curve of friction factor and time

The curve of friction coefficient recession and time is as shown in fig8. the temperature of brake disc is less than $102.74^{\circ} \mathrm{C}$ from the beginning of braking to the $50.06 \mathrm{~s}$, the friction coefficient of braking does not change, the rate of recession is zero; from 50.06 s to 301.18 s, the temperature of brake disc increases from $102.74{ }^{\circ} \mathrm{C}$ to $246.84{ }^{\circ} \mathrm{C}$, friction coefficient increases at first and then decreases, the overall increases slightly, the rate of recession is negative; from 301.18s to the end of time 720 s, the temperature of brake disc increases nonlinearly, the maximum value is $316.04^{\circ} \mathrm{C}$, friction coefficient decreases continuously, the minimum value is 0.36 , the rate of recession declines increasing, the maximum value is $8.16 \%$. 


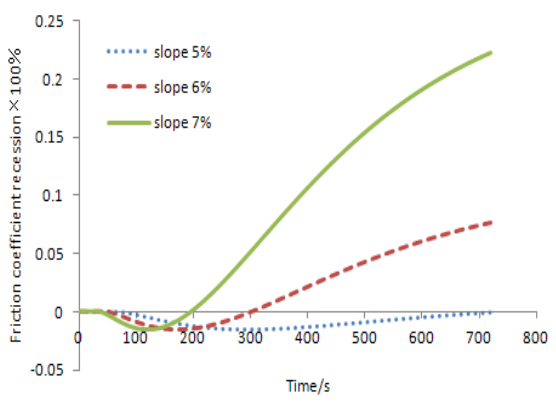

Figure 8. The curve of friction coefficient recession and time

\section{CONCLUSION}

1) The initial velocity is $30 \mathrm{~km} / \mathrm{h}$, slope is $6 \%$, simulation and analysis of 3D transient temperature field of brake disc under long downhill braking conditions by finite element software ANSYS. The maximum temperature of brake disc is $316.04{ }^{\circ} \mathrm{C}$ at the end of braking. During braking, the temperature increased gradually with the increasing of time.

2) By the analysis of distribution of transient temperature field of brake disc under long downhill braking conditions, it obtains that density of heat flux increases with the increasing of friction radius, temperature gradient in the radial direction is larger; Thermal conduction and convection are enough, temperature gradient in the axial direction is nearly uniform.

3) The friction coefficient and friction coefficient varied with time are calculated during long downhill braking conditions under different slope. The maximum rate of recession is $8.16 \%$, friction coefficient is always stable within a reasonable range, the obvious thermal recession is not happened.

\section{References}

[1] Choi. J. H, Lee. I. Transient thermo elastic analysis of disk brakes in frictional contact[J].Journal of Thermal Stresses, 2003, 26: 223.

[2] M. Eltoukhy, S. Asfour, M. Almakky, C. Huang, "Thermoelastic Instability in Disk Brakes: Simulation of the Heat Generation Problem," Proceedings of the COMSOL Users Conference, Boston, USA, 2006.

[3] Kwangjin Lee, "Frictionally excited thermoelastic instability in disc brakes,” International Journal of Mechanical Sciences, Vol. 49, 2007, pp. 129-137.

[4] HUANG Jianmeng, GAO Chenghui, TANG Xusheng and LIN Xiezhao, "Numerical Modeling and Analysis of the Thermalstructure Coupling of the Disc Brake," CHINESE JOURNAL OF MECHANICAL ENGINEERING, Vol. 44, No. 2, 2008, pp. 145-150.

[5] C.H.Gao, J.M.Huang, X.Z.Lin, X.S.Tang, "Stress Analysis of Thermal Fatigue Fracture of Brake Disks Based on Thermomechanical Coupling,” Transactions of the ASME, Vol. 129, 2007, pp.536-543.

[6] Xun Yang, Ji-xin Wang, Jiu-chen Fan, "Simulation Study of Temperature Field and Stress Field of Disc Brake Based on Direct Coupling Method,” The 13th International Manufacturing Conference in China (IMCC), 2009. Materials Science Forum, Vol. 628-629, 2009, pp. 287-292.

[7] Zheng zhu jian. Numerical calculation of temperature field Aircraft brake during braking. Computer Simulation. 2007.24(9). In chinese.

[8] Xi min zhang. Theory of heat transfer[J]. China Building Industry Press.2008. In chinese. 